\title{
Análise dos acidentes de trânsito ocasionados por animais nas rodovias federais do estado de Pernambuco, Brasil
}

\author{
[Analysis of traffic accidents caused by animals on federal highways in the state of Pernambuco, \\ Brazil]
}

\section{"Artigo Científico/Scientific Article"}

\author{
Jenner Mendes Muniz Jardim ${ }^{1,2}$, Rafael Artur da Silva Júnior ${ }^{1}$, Ingrid Cavalcanti Pascoal ${ }^{1}$, \\ Andrea Alice da Fonseca Oliveira ${ }^{1, *}$, José Wilton Pinheiro Junior ${ }^{1}$
}

\author{
${ }^{1}$ Departamento de Medicina Veterinária, Universidade Federal Rural de Pernambuco, Recife-PE, Brasil. \\ ${ }^{2}$ Polícia Rodoviária Federal, Departamento de Polícia Rodoviária Federal, Recife-PE, Brasil. \\ *Autor para correspondência/Corresponding author: E-mail: andreaafo@ hotmail.com
}

\begin{abstract}
Resumo
Objetivou-se analisar durante o triênio 2012-2014 as ocorrências de acidentes de trânsito ocasionados por animais nas rodovias federais do estado de Pernambuco, com base em informações obtidas no banco de dados do sistema operacional da Polícia Rodoviária Federal, o Siger2. Foram analisadas as variáveis: quantitativo de acidentes por ano, tipo de veículo, rodovia de ocorrência, tipo de pista, traçado da via, condições meteorológicas, fase do dia, tipo do solo (perímetro da via), sexo, idade dos condutores e estado físico das vítimas. No triênio de 2012 a 2014 foram registrados 1.013 acidentes do tipo atropelamento animal. Constatouse maior ocorrência de acidentes no ano de 2012 (40,1\%), ocasionados por automóveis (46,9\%), na BR 232 $(37,5 \%)$, em pista simples $(72,8 \%)$ com trechos em linha reta $(92,8 \%)$, em céu claro $(67,4 \%)$, fase de plena noite $(65,7 \%)$, e no perímetro rural $(72,2 \%)$. Predominaram os condutores do sexo masculino $(86,3 \%)$, com idade entre 18 a 40 anos (54,5\%) e 63,3\% das vítimas foram classificadas como ilesas. Considera-se fundamental a implementação de políticas públicas e medidas mitigatórias que forneçam subsídios para melhorias na conservação e sinalização das rodovias, bem como a elaboração de programas destinados a minimizarem o acesso dos animais as rodovias e campanhas educativas direcionadas aos tutores de animais e condutores, sendo a participação do médico veterinário essencial na elaboração e implementação dessas medidas.
\end{abstract}

Palavras-Chave: atropelamento animal, condutores, levantamento, polícia rodoviária federal.

\begin{abstract}
The objective of this study was analyzed during the triennium 2012-2014 occurrences of traffic accidents caused by animals in federal highways of Pernambuco state based on information obtained from the operating system of the database of the Federal Highway Police, Siger2. The following variables were analyzed: accidents per year, vehicle type, accident occurrence for federal highway, type and layout of the track, meteorological conditions, day phase, soil type (track perimeter), sex, the age of drivers and physical state of victims. In the period 2012-2014 were recorded 1,013 occurrences of traffic accidents caused by animals. It found a higher incidence of accidents in the year $2012(40.1 \%)$, caused by cars (46.9\%), in the federal highway $232(37.5 \%)$ in single lane (72.8\%) with stretch of track in straight line (92.8\%) in clear sky (67.4\%), night full phase $(65.7 \%)$, and in rural area (72.2\%). Predominated male drivers $(86.3 \%)$, aged $18-40$ years $(54.5 \%)$ and $63.3 \%$ of the victims were classified as unscathed. It is fundamental the implementation of public policies and mitigation measures that provide subsidies to improve the conservation and signaling of roads and the development of programs to minimize animal's access to highways, as well as educational campaigns directed to animal guardians and drivers, being the participation of the veterinarian essential in the elaboration and implementation of these measures.
\end{abstract}

Key-words: roadkill animal, drivers, survey, federal highway police. 


\section{Introdução}

O Brasil possui um dos maiores rebanhos semovente do mundo (REIS, 2003), paralelo a isso Freitas e Barszcz (2015) enfatizam que boa parte de acidentes registrados ocorre com envolvimento de animais que circulam pelas rodovias, adicionado ao fato que os condutores encaram do mesmo modo dificuldades rotineiras que provém principalmente da má conservação rodoviária, o que os vulneráveis a ocorrências com consequências que vão de prejuízos materiais a óbitos.

A Polícia Rodoviária Federal (PRF) é a autarquia responsável pelo registro dos acidentes nas rodovias federais brasileiras, sendo este realizado por meio de boletim de ocorrência de acidente de trânsito. No boletim encontram-se informações referentes ao acidente, tais como: data, horário, rodovia, localização, condições meteorológicas, fase do dia, tipo de acidente, causa presumível, veículo(s) e condutor(es) envolvidos, além de danos e dinâmica do acidente (Freitas e Barszcz, 2014).

De acordo com a Polícia Rodoviária Federal (PRF, 2014) a presença de animais na pista é considerada a oitava maior causa de acidentes em rodovias federais do Brasil, superando o sono, ultrapassagem indevida e infraestrutura da via, além de ser a nona causa de acidentes com vítimas fatais.

A caracterização dos fatores de risco relacionados às colisões de veículos com animais é essencial, uma vez que o conhecimento desses fatores permite a elaboração de estratégias de prevenção na tentativa de reduzir a morbidade, mortalidade e custos associados aos acidentes (Langley et al., 2006).

Desta forma, a participação do médico veterinário em programas que visem minimizar a ocorrência de acidentes deste tipo é essencial, principalmente na qualidade de educador $\mathrm{e}$ profissional atuante na saúde pública.

Diante da magnitude dos danos determinados pelos acidentes do tipo atropelamento animal, tanto do ponto de vista material quanto das ocorrências de lesões e óbitos, bem como da importância da atuação dos médicos veterinários, juntamente a órgãos governamentais, na adoção de medidas preventivas, objetivou-se com este estudo analisar as ocorrências de acidentes de trânsito ocasionados por animais nas rodovias federais do estado de Pernambuco.

\section{Material e Métodos}

Foram avaliadas 1.013 ocorrências de acidentes de trânsito ocasionados por animais nas rodovias federais do estado de Pernambuco ($\left.8^{\circ} 19^{\prime} 59 \mathrm{~S} ; \mathbf{3}^{\circ} 45^{\prime} 00\right)$ localizado na Região Nordeste do Brasil, entre os anos de 2012 e 2014. Para obtenção das variáveis utilizou-se o banco de dados do sistema operacional da PRF, o Siger2.

As seguintes variáveis foram analisadas:

- Quantitativo de acidentes do tipo atropelamento animal por ano;

- Tipo de veículo envolvido na ocorrência: automóvel, motocicleta, caminhonete, caminhão, trator, camioneta, carroça, ciclomotor, microônibus, motoneta, ônibus, utilitário, não se aplica (outros veículos, ex. bicicleta) e não identificado (ausência do veículo no local da ocorrência);

- Rodovia de ocorrência e tipo de pista: simples (sem separadores físicos entre as faixas de rodagem, mão dupla ou não), dupla (duas faixas de rodagem separadas por elemento físico, mão dupla ou não) e múltipla (mais de um separador nas faixas de rodagem);

- Traçado da via: em curva e reta, a análise considerou o local de ocorrência dos acidentes;

- Condições meteorológicas;

- Fase do dia: foram consideradas ocorrências durante as seguintes fases: amanhecer, anoitecer, plena noite e pleno dia.

- Tipo de solo (perímetro da via): na variável tipo de solo, subdividida em rural e urbano, considerou-se o local de ocorrência do acidente, uma vez que algumas rodovias permeiam entre ambos os ambientes.

- Características demográficas: sexo (masculino, feminino e inválido) e idade dos condutores envolvidos em acidentes com animais. De acordo com as informações disponíveis no sistema a idade foi estratificada em $<18$ anos, entre 18 e 40 anos e > 40 anos;

- Estado físico das vítimas em relação ao acidente: ileso (sem lesões detectadas relacionadas ao acidente), leve (vítimas que apresentaram dores em geral, traumas leves, queimaduras de 10 grau, fraturas dentárias, pequenas hemorragias externas, pequenas fraturas, luxações ou entorses, contusão cerebral leve), grave (vítimas não classificadas como leve ou não tenham como resultado o óbito), morto (óbito confirmado no local) e ignorado (sem informações a respeito do estado da vítima, após esgotadas as possibilidades de verificação). 
Para análise dos dados realizou-se a dispersão das frequências absoluta e relativa com auxílio dos softwares Excel e EPIINFO 3.5.1.

\section{Resultados e Discussão}

De acordo com os dados obtidos no Singer2 da PRF no triênio de 2012 a 2014 foram registradas 1.013 ocorrências relacionadas a acidentes do tipo atropelamento animal nas rodovias federais do estado de Pernambuco, destas 40,1\% (406) ocorreram no ano de 2012, 36,8\% (373) em 2013 e $23,1 \%$ (234) no ano de 2014.

Constatou-se maior ocorrência de acidentes no ano de 2012, entretanto percebe-se claramente que houve uma redução gradativa no número de acidentes no decorrer dos anos, o que pode refletir as ações efetivas de fiscalização e atuação da PRF no sentido de retirar os animais das rodovias. Há de se supor também que a seca que atingiu o estado, neste período, reduziu o número do rebanho e os animais foram deslocados para locais onde havia água, o que reduziria a quantidade de animais expostos.

No estado de Sergipe, também localizado na região nordeste do Brasil, segundo a Companhia de Polícia Rodoviária Estadual (CPRv), a quantidade de acidentes com envolvimento de animais, diminuiu drasticamente no início de 2014. Atribuiu-se essa redução ao trabalho preventivo realizado no estado com o recolhimento efetivo dos animais que transitavam nas vias (Globo
Comunicação, 2014). Entretanto, ressalta-se que informações sobre ocorrências de acidentes do tipo atropelamento de animal são escassos na região nordeste, o que dificulta a elaboração de uma análise mais aprofundada sobre a questão, assim como a não obrigatoriedade na identificação dos animais, no que concerne a espécie e porte, por exemplo, nos boletins de ocorrência de acidentes de trânsito emitidos pela PRF conforme observado por Freitas e Barszcz (2014).

Esse lapso documental dificulta a identificação do proprietário ou tutor dos animais e a consequente responsabilização de quem deu causa ao acidente, do mesmo modo que dificulta um traçado mais preciso das principais espécies envolvidas nos acidentes e quais seriam as melhores estratégias de prevenção.

Cabe ressaltar ainda, que no Brasil inexiste uma legislação específica em situações de acidente de trânsito do tipo atropelamento de animais. Entretanto, o dono ou detentor do animal responderá pelos danos ocasionados a terceiros, se não houver provas de culpa da vítima ou por força maior, de acordo com o artigo 936 do Código Civil (Brasil, 2002).

Em relação aos tipos de veículos envolvidos nos acidentes para o referido período, os dados encontram-se dispostos na Tabela 1. Os automóveis foram responsáveis por $47,1 \%$ (478/1013) dos casos registrados durante o triênio analisado.

Tabela 1. Tipos de veículos envolvidos em acidentes do tipo atropelamento animal ocorridos no estado de PernambucoBrasil, durante o triênio 2012-2014.

\begin{tabular}{lcccc}
\hline \multirow{2}{*}{ Tipo de veículo } & \multicolumn{3}{c}{ Ano } & \multirow{2}{*}{ Total do Triênio } \\
\cline { 2 - 4 } & $\mathbf{2 0 1 2}$ & $\mathbf{2 0 1 3}$ & $\mathbf{2 0 1 4}$ & \\
\cline { 2 - 4 } & \multicolumn{3}{c}{ Número de Acidentes $(\%)$} & $478(47,1 \%)$ \\
\hline Automóvel & $183(45,1)$ & $191(51,2)$ & $104(44,4)$ & $183(18,0 \%)$ \\
Motocicleta & $83(20,4)$ & $61(16,4)$ & $39(16,7)$ & $150(15,0 \%)$ \\
Caminhonete & $59(14,5)$ & $58(15,5)$ & $33(14,1)$ & $69(7,0 \%)$ \\
Caminhão & $32(7,9)$ & $26(7,0)$ & $11(4,7)$ & $36(3,5 \%)$ \\
Trator & $12(3,0)$ & $17(4,6)$ & $7(3,0)$ & $28(2,5 \%)$ \\
Camioneta & $8(2,0)$ & $10(2,7)$ & $10(4,3)$ & $20(2,0 \%)$ \\
Micro-ônibus & $10(2,5)$ & $3(0,8)$ & $7(3,0)$ & $15(1,5 \%)$ \\
Ônibus & $5(1,2)$ & $2(0,5)$ & $8(3,4)$ & $11(1,1 \%)$ \\
Não se aplica & $6(1,5)$ & $1(0,3)$ & $4(1,7)$ & $10(1,0 \%)$ \\
Utilitário & $3(0,7)$ & $3(0,7)$ & $4(1,7)$ & $7(0,7 \%)$ \\
Não identificado & $4(1,0)$ & $1(0,3)$ & $2(0,9)$ & $4(0,4 \%)$ \\
Motonetas & $1(0,2)$ & - & $3(1,3)$ & $1(0,1 \%)$ \\
Carroça & - & - & $1(0,4)$ & $1(0,1 \%)$ \\
Ciclomotor & - & - & $1(0,4)$ & $1.013(100 \%)$ \\
\hline Total por Ano & $406(40,1)$ & $373(36,8)$ & $234(23,1)$ & \\
\hline
\end{tabular}


Em relação ao tipo de veículo envolvido, Freitas e Barszcz (2015) em levantamento realizado com base em informações obtidas na mídia online sobre acidentes com envolvimento de animais, no período de 2007 a 2012, registraram que os automóveis foram o tipo de veículo mais envolvido nestes casos, correspondendo a aproximadamente $69,6 \%$ (87/125) do efetivo de acidentes, quando comparados a outros tipos de veículos.

A maior ocorrência de veículos dos tipos automóvel, seguido por motocicleta e caminhonete foi sugestiva da própria quantidade absoluta dos veículos existentes nas localidades com maior número de ocorrências. Fato constatado pelo
Departamento Estadual de Transito de Pernambuco (DETRAN-PE, 2016) que contabilizou, em média, 46,52\% (3.429.274/7.371.066) de automóveis para o triênio 2012-2014 no estado, número aproximado à quantidade de ocorrências com este tipo de veículo para o mesmo período.

As ocorrências foram analisadas em 11 rodovias do estado de Pernambuco, do total de 14 existentes. As rodovias que não foram analisadas não apresentaram registros de ocorrência no sistema de acidente do tipo atropelamento animal para o referido período. As rodovias BR-232, BR428 e BR-101 foram as que apresentaram o maior número de registros de acidentes (Figura 1).

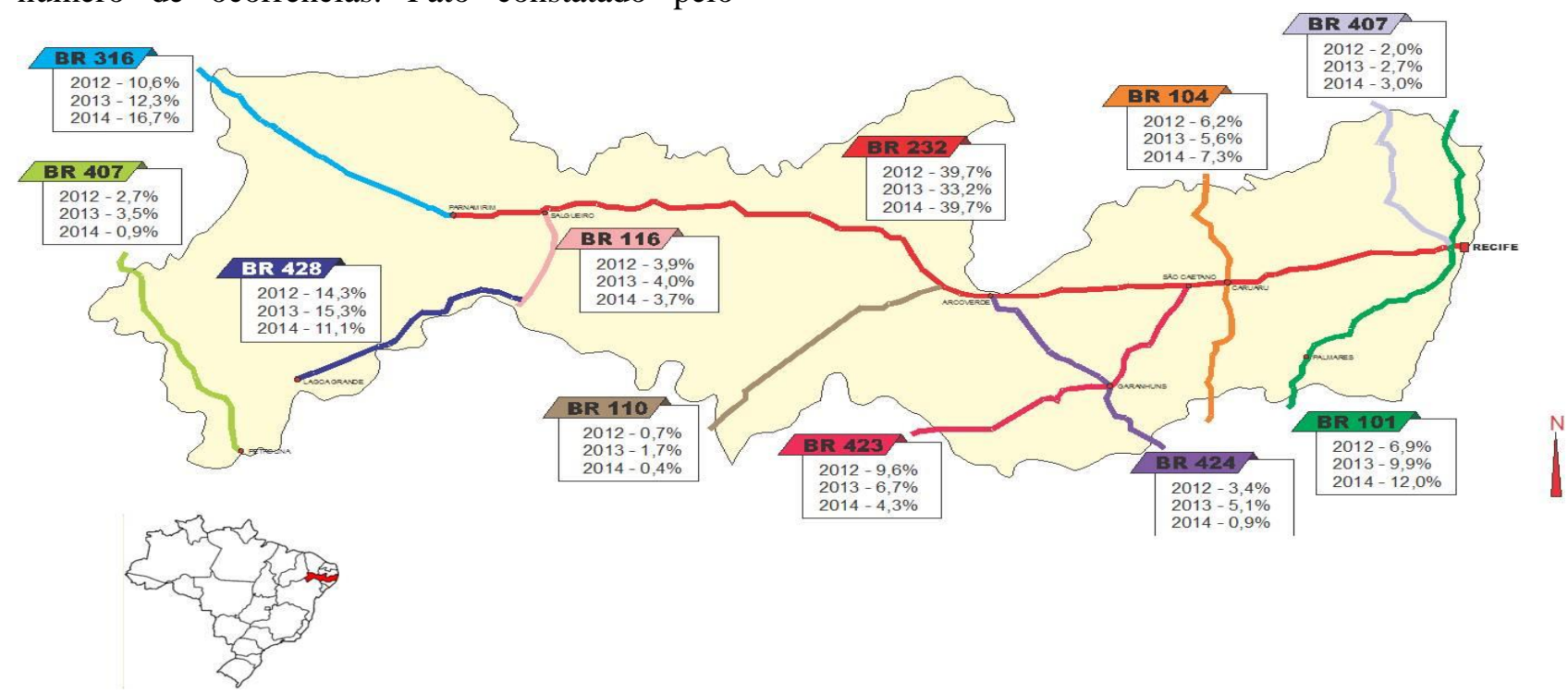

Figura 1. Análise dos acidentes do tipo atropelamento animal por rodovias do estado de Pernambuco-Brasil, durante o triênio 2012 2014.

A rodovia BR-232 destacou-se com maior número de ocorrência de acidentes $(37,5 \%)$ para o referido triênio, o que pode ser explicado pelo fato de ser a de maior extensão no estado com mais de 500 quilômetros de malha e promover a integração leste-oeste, passando por inúmeros centros urbanos e aglomerações, além de apresentar intenso fluxo diário.

A BR-428, em segundo lugar no registro de acidentes, apresentou média de $13,5 \%$ de ocorrências no triênio. Essa rodovia propicia o acesso às cidades de Belém de São Francisco e Petrolina, localizadas no estado, possuindo às suas margens, o canteiro de obras da transposição do Rio São Francisco (eixo oeste) e a cidade base de Cabrobó. Além disso, atravessa o perímetro irrigado do vale do São Francisco com seu movimento intenso de transporte de hortifrúti. Por sua vez a BR-101 transpõe o estado no sentido norte-sul servindo polos industriais, turísticos e ainda atendendo a região metropolitana do Recife, capital do estado. Neste estudo a média de acidentes registrados nesta rodovia representou 9,6\%, durante o período de 2012 a 2014.

A redução dos acidentes na BR-407 entre os anos de 2013 a 2014, no sertão do São Francisco, com destaque ao município de Petrolina e adjacências, está vinculada a grande influência das ações realizadas pela PRF e parceiros, que promovem a apreensão e guarda dos animais, em locais apropriados, que se encontram na faixa de domínio da união que margeia as rodovias.

O resultado de acidentes ocorridos nos diferentes tipos de pista, considerando-se o efetivo de ocorrências por ano, encontra-se representado na Figura 2. 


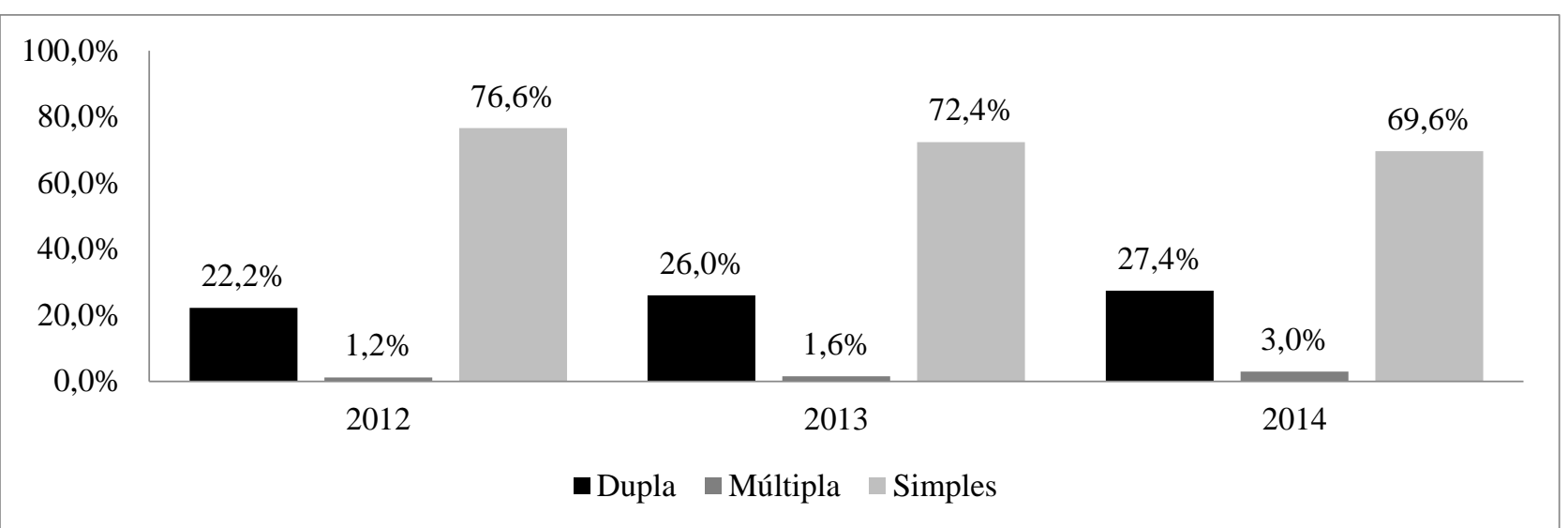

Figura 2. Ocorrência de acidentes em relação ao tipo de pista nas rodovias do estado de Pernambuco-Brasil, no triênio 2012-2014.

Dados do Instituto de Pesquisa Econômica Aplicada - IPEA (2015) demonstraram que no ano de 2014 no Brasil, 89,71\% (7.380/8.227) dos acidentes de ordem geral com óbitos ocorreram por colisão frontal em pista simples. Mesmo tipo de via registrada neste estudo, com média de $72,8 \%$ dos acidentes envolvendo animais, destacando que a possibilidade de ocorrências eleva-se neste tipo de pista. O trânsito nos dois sentidos deste tipo de via dificulta manobras de evasão e desvios o que pode acarretar em acidentes graves. As circunstâncias que sugerem maior predisposição para a ocorrência acidentes também estão presentes nestes trechos, como a criação de animais de forma extensiva e a presença de asininos na área de domínio da união. A ausência de ações extensionistas, por meio de campanhas educativas e transferência de tecnologias, envolvendo médicos veterinários e zootecnistas no estado e Pernambuco contribui de forma significativa para a criação desordenada de animais favorecendo a saída destes para as rodovias.

Em relação ao traçado da via em Pernambuco, os dados foram analisados considerando-se trechos em linha reta e curva.
Destaca-se o fato que $92,8 \%$ dos acidentes, para os três anos pesquisados, ocorreram nos trechos em linha reta, sumariamente trechos em curva deveriam concentrar a maioria dos acidentes, entretanto tal fato pode ser explicado pela velocidade imposta pelo condutor em linha reta, por vezes excessiva e muitas vezes incompatível com a via, o que impossibilita o desvio de animais na pista.

Langley et al. (2006) detectaram, em estudo realizado nos Estados Unidos com acidentes do tipo atropelamento animal, a maior propensão para ocorrência em traçados em linha reta, resultados semelhantes ao obtidos nesta análise.

Embora a velocidade seja fator considerável para elevar a estatística de acidentes nos traçados em linha reta, ressalta-se que situações propícias a acidentes, mesmo aqueles com envolvimento de animais, podem ser criadas na presença de um ambiente viário mal projetado, sem sinalização e com condições precárias de pavimentação.

Outra variável analisada neste estudo referese às condições meteorológicas no local do acidente, considerando-se o efetivo de ocorrências por ano (Figura 3).

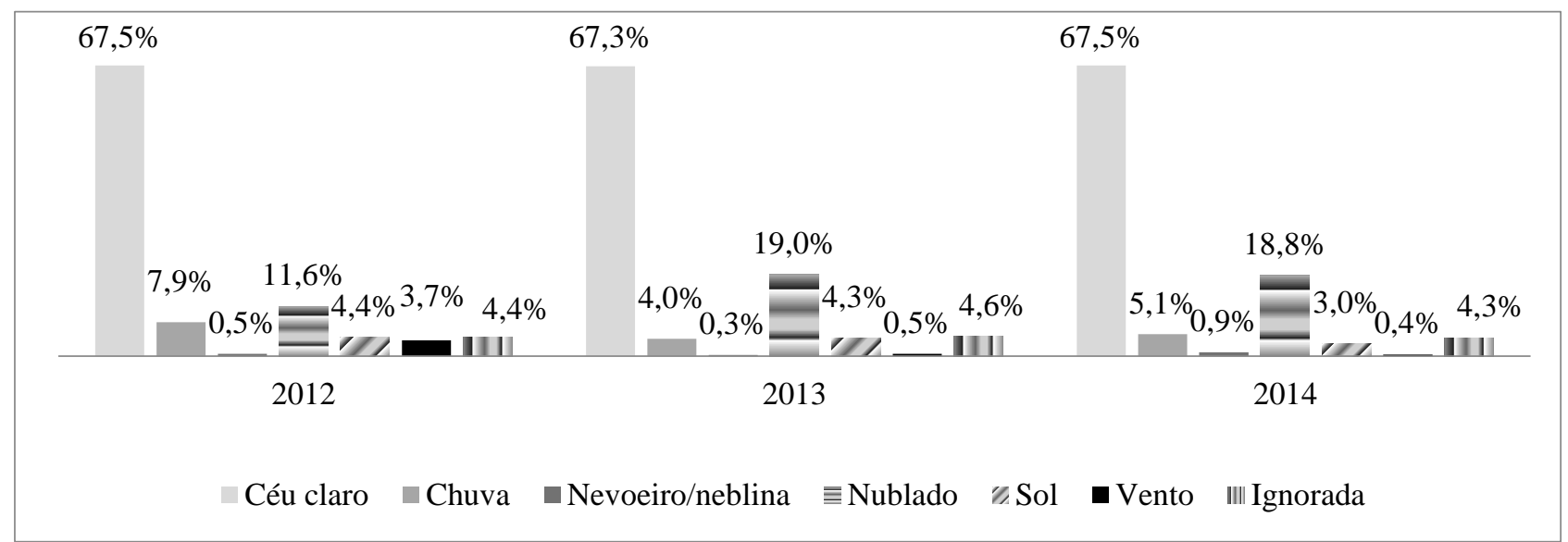

Figura 3. Ocorrência de acidentes em relação às condições meteorológicas nas rodovias do estado de Pernambuco - Brasil, no triênio 2012-2014. 
Em média 67,4\% dos acidentes ocorreram na condição de céu claro em Pernambuco, refletindo a condição meteorológica predominante no estado e demonstrando que o excesso de confiança dos motoristas em condições normais de tempo, eleva expressivamente a quantidade de ocorrências nessa categoria, uma vez que em condições climáticas desfavoráveis há naturalmente a tendência em reduzir-se a velocidade.

Do mesmo modo, Višnjiæ e Pušiæ (2009) na Croácia constataram que de 627 acidentes, analisados no período de dois anos e oriundos de causas diversas, 52,1\% (327) ocorreram com o tempo considerado bom.

Com relação a variável tipo de solo (perímetro da via) em que foi notificada a ocorrência, nas rodovias que atravessam áreas rurais de Pernambuco foram detectados para o triênio uma média de $72,2 \%$ dos acidentes envolvendo motoristas e animais, por sua vez nas rodovias predominantemente urbanas a média decresce para $27,8 \%$.

$\mathrm{O}$ perímetro rural foi considerado fator de risco $(\mathrm{OR}=6,03)$ por Langley et al. (2006) nos Estados Unidos, em levantamento realizado no período de 1995 a 2004, para acidentes com e sem envolvimento de animais.

A redução de acidentes nos perímetros urbanos, quando comparado ao rural, deve-se ao fato de que nestes se encontram instalados redutores de velocidade e possuem iluminação durante a noite, fatores estes que exercem forte influência no número de ocorrências. Há de se considerar o fato que na zona rural a presença de animais, principalmente de grande porte faz-se presente de forma significativa o que aumenta a probabilidade de saída destes para as rodovias.
Foram analisadas as ocorrências notificadas durante o triênio 2012-2014 quanto ao aspecto fase do dia. A dificuldade de visualização geralmente é apontada como principal causa para ocorrência dos acidentes, neste estudo em média $65,73 \%$ ocorreram na fase plena noite, seguido pelas fases pleno dia $(17,13 \%)$ e amanhecer $(8,76 \%)$. Queixas frequentes são registradas de animais que adentram repentinamente nas rodovias e não são de pronto detectado pelos condutores.

A dificuldade de visualização geralmente é apontada como principal causa para ocorrência dos acidentes, neste estudo em média 65,73\% ocorreram na fase plena noite. Queixas frequentes são registradas de animais que adentram repentinamente nas rodovias e não são de pronto detectado pelos condutores.

Resultados semelhantes foram obtidos por Leger (1994) que analisou no período de um ano acidentes de transito de causas diversas, nos Estados Unidos e concluiu que 54\% destes ocorreram na fase plena noite, valores atribuídos ao tempo de reação e desempenho diminuídos, além do fato da privação e interrupção do sono, o que favorece sonolência ao volante. Do mesmo modo, valores semelhantes foram obtidos por Freitas e Barszcz (2015), quando comparados ao presente estudo, em levantamento realizado na internet sobre acidentes envolvendo animais em rodovias, no período de 2007 a 2012. Os autores constataram que dos 125 acidentes analisados 68,54\% ocorreram à noite ou de madrugada.

As ocorrências também foram analisadas em relação ao estado físico dos ocupantes, nos acidentes com envolvimento de animais (Tabela 2).

Tabela 2. Ocorrência de acidentes em relação ao estado físico da vítima nas rodovias do estado de Pernambuco - Brasil, no triênio 2012-2014.

\begin{tabular}{ccccc}
\hline \multirow{2}{*}{$\begin{array}{c}\text { Estado Físico das } \\
\text { Vítimas }\end{array}$} & \multicolumn{3}{c}{ Ano } & Total por Estado \\
\cline { 2 - 4 } & $\mathbf{2 0 1 2}$ & $\mathbf{2 0 1 3}$ & $\mathbf{2 0 1 4}$ & Físico das Vítimas \\
\cline { 2 - 4 } & \multicolumn{4}{c}{ Número de Acidentados $(\%)$} \\
\hline Ileso & $229(56,5)$ & $265(71,0)$ & $146(62,4)$ & $640(63,2 \%)$ \\
Leve & $98(24,1)$ & $72(19,3)$ & $51(21,8)$ & $221(21,8 \%)$ \\
Grave & $56(13,8)$ & $26(7,0)$ & $25(10,7)$ & $107(10,5 \%)$ \\
Morto & $16(3,9)$ & $7(1,9)$ & $7(3,0)$ & $30(3,0 \%)$ \\
Ignorado & $7(1,7)$ & $3(0,8)$ & $5(2,1)$ & $15(1,5 \%)$ \\
\hline Total por Ano & $406(40,1)$ & $373(36,8)$ & $234(23,1)$ & $1013(100 \%)$ \\
\hline
\end{tabular}

No presente estudo detectou-se em média para o triênio que em relação ao estado físico 63,2\% das vítimas foram classificadas como ilesa,
$21,8 \%$ com presença de lesões de natureza leve, $10,5 \%$ com lesões de natureza grave, $3 \%$ de vítimas 
fatais e em $1,5 \%$ das ocorrências registradas essa informação foi ignorada.

A análise de 125 notícias de acidentes obtidas pela internet, envolvendo veículos e animais, realizada por Freitas e Barszcz (2015) resultou em $28,5 \%$ de vítimas fatais e $71,5 \%$ pessoas feridas, contradizendo os resultados obtidos neste estudo. Atribuiu-se essa discordância ao universo de dados pesquisados, enquanto neste estudo foram analisadas todas as ocorrências do triênio, naquele apenas os acidentes que foram noticiados na internet, o que pode sugerir que acidentes de pequena monta ou sem feridos deixaram de ser noticiados na internet e desta forma não participaram da análise.

Outras variáveis analisadas no estudo foram o sexo e a idade dos condutores, considerando-se o efetivo de ocorrências por ano (Figuras 4 e 5).

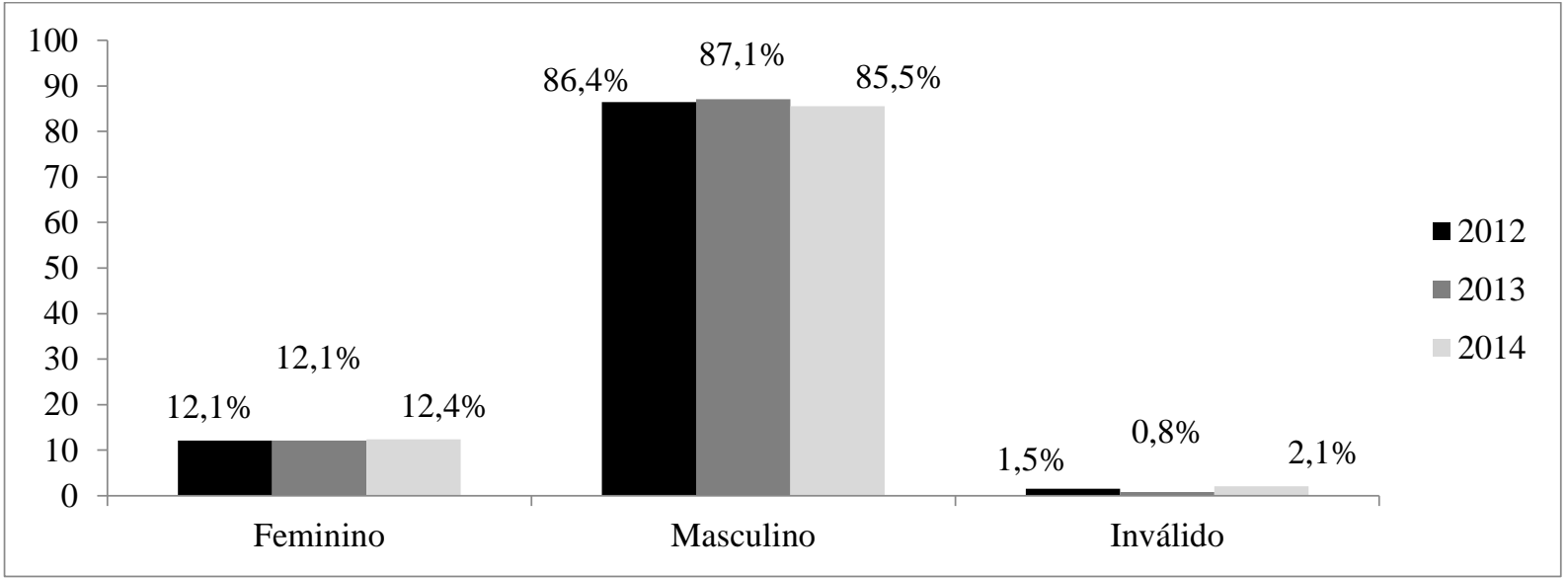

Figura 4. Ocorrência de acidentes em relação ao sexo do condutor nas rodovias do estado de Pernambuco no triênio 2012 2014.

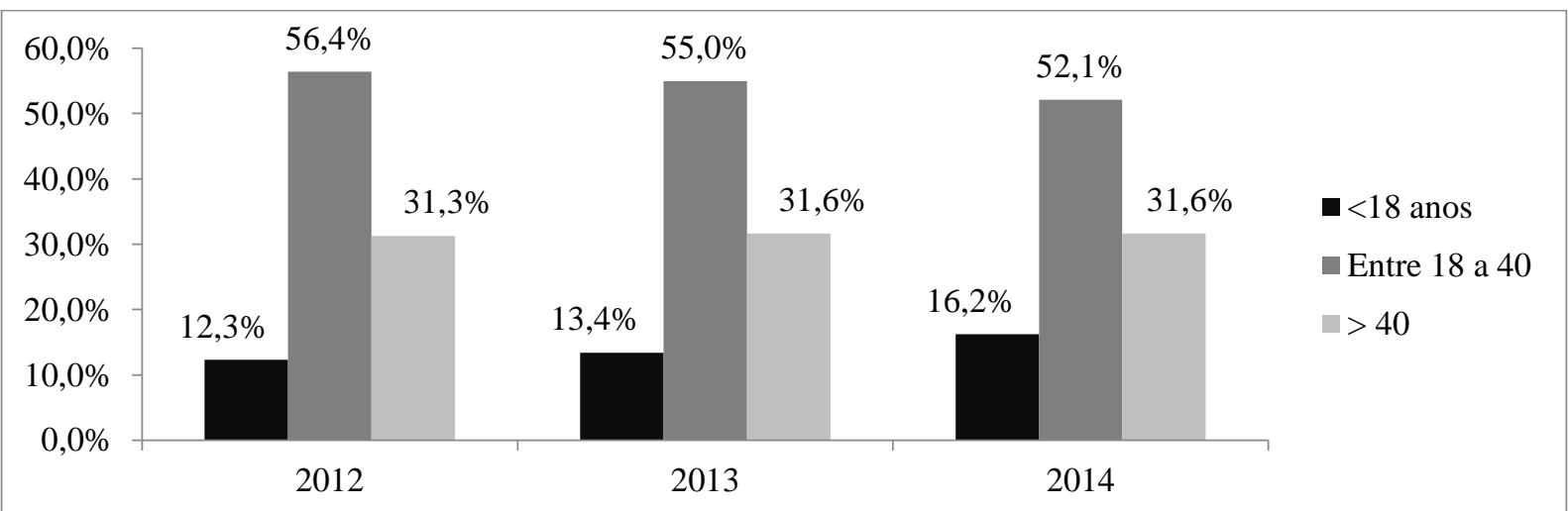

Figura 5. Ocorrência de acidentes em relação à idade (anos) do condutor nas rodovias do estado de Pernambuco no triênio 2012-2014.

Na rotina de fiscalização e atendimento de acidentes rodoviários nas rodovias federais do estado de Pernambuco, observou-se em média a predominância de condutores do sexo masculino $(86,3 \%)$ com idade compreendida entre 18 e 40 anos $(54,5 \%)$ nos anos analisados. No aspecto referente aos acidentes do tipo atropelamento animal que em sua maioria ocorreram no período noturno e fora dos perímetros urbanos a maior frequência relativa desse perfil de condutor refletiu a predominância, em números absolutos, de adultos jovens como condutores nesse período e local.

No Anuário Estatístico das Rodovias Federais (DNIT, 2010) para o triênio 2008-2010 foram registrados 830.759 acidentes de trânsito de causas diversas, destes $87,4 \%$ ocorreram com condutores do sexo masculino e $56 \%$ possuía idade variando entre 18 e 40 anos.

Considerando ainda os dados do Departamento Nacional de Infraestrutura de Transportes (DNIT, 2012) para o ano de 2011 no estado de Pernambuco, do efetivo total de 13.535 ocorrências incluindo acidentes do tipo atropelamento animal, atribuiu-se 91,9\% dos acidentes aos condutores do sexo masculino e destes $56,9 \%$ pertenciam à faixa etária de 18 a 40 anos, resultados semelhantes ao presente estudo reafirmando o mesmo perfil nos anos subsequentes.

A predominância de condutores adultos jovens do sexo masculino com envolvimento em acidentes de trânsito está relacionada a uma 
diversidade de fatores: pouca prática na condução de veículos (Kaiser, 1979), condução mais agressiva, impaciência, desafio à lei pelo excesso de velocidade (Marín e Queiroz, 2000), a concepção de que carros velozes e altas velocidades associam-se a virilidade (WHO, 1976), além da falta de atenção e ingestão prévia de bebidas alcoólicas (Andrade et al., 2003). Em síntese esses condutores assumem comportamento de risco de forma mais frequente quando comparados aos do sexo feminino, contribuindo com as estatísticas de acidentes de trânsito e dentre estes os acidentes do tipo atropelamento animal.

O médico veterinário como promotor da saúde animal e atuante no âmbito extensionista apresenta qualificação técnica indispensável na elaboração de medidas preventivas, tais como a orientação de produtores rurais que evitem deixar soltos os animais nas proximidades de estradas, alertar para colocação de cercas adequadas, entre outras que objetivem a redução no número de acidentes com envolvimento animal, na qualidade de conhecedor das características de diferentes espécies, incluindo os animais silvestres.

A ausência de dados relacionados às principais espécies envolvidas nestes acidentes dificulta o direcionamento dessas medidas, de modo que se faz necessário ressaltar as autoridades competentes a importância da notificação das espécies envolvidas em acidentes do tipo atropelamento animal e deste modo possibilitar a implementação de medidas forma multidisciplinar.

\section{Conclusão}

Os acidentes com envolvimento de animais nas rodovias federais brasileiras e particularmente no estado de Pernambuco consistem em problema de saúde pública, gerando gastos extras ao estado. Com base no conhecimento dos fatores que compõem estas ocorrências é possível estudar novas estratégias que permitam reduzir estes acidentes. Considera-se fundamental a implementação de políticas públicas e medidas mitigatórias que forneçam subsídios para melhorias na conservação e sinalização das rodovias, bem como a elaboração de programas de controle destinados a minimizarem o acesso dos animais as rodovias, além de campanhas educativas direcionadas aos tutores destes animais e condutores com a efetiva colaboração de profissionais capacitados, tais como médicos veterinários.

\section{Conflito de Interesse}

Os autores declaram não existir conflito de interesse.

\section{Agradecimentos}

Ao Departamento de Polícia Rodoviária Federal no estado de Pernambuco.

\section{Referências}

Andrade, S.M.; Soares, D.A.; Braga, G.P.; Moreira, J.H.; Botelho, F.M.N. Risky behavior for traffic accidents: a survey among medical students in Southern Brazil. Revista da Associação Médica Brasileira, 49: 439444, 2003.

BRASIL. Novo Código Civil Brasileiro. Lei $\mathbf{n}^{\mathbf{0}}$ 10.406, de 10 de janeiro de 2002. Legislação Federal, 2002. Disponível em: $<$ http://www.planalto.gov.br-

/ccivil_03/leis/2002/110406.htm>. Acesso em: 10 nov. 2016.

DETRAN-PE - Departamento Estadual de Trânsito de Pernambuco Estatísticas. Recife, 2016. Disponível $<$ http://www.detran.pe.gov.br/index.php?opti on-comcontenteview-articleeid $=36$ :estatisticas-atuaisecatid $=26$ :estatisticasatuaiseItemid-72>._Acesso em: 28 out. 2016.

DNIT - Departamento Nacional de Infraestrutura de Transportes. Anuário estatístico das rodovias federais 2010: Acidentes de trânsito e ações de enfrentamento ao crime. Brasília, 2010. 687p. Disponível em: <http://www.dnit.gov.br/rodovias/operacoesrodoviarias/estatisticasde acidentes/anuario2010.pdf.> Acesso em: 17 nov. 2016.

DNIT - Departamento Nacional de Infraestrutura de Transportes. Estatísticas de acidentes. 2012. p. 28. Disponível em: <http://189.9.128.64/download/rodovias/oper acoes-rodoviarias/estatisticas-deacidentes/quadro-0302-numero-decondutores-envolvidos-por-sexo-e-idade-docondutor-ano-de-2011.pdf.> Acesso em: 17 nov. 2016.

Freitas, S.R.; Barszcz, L. B. A perspectiva da mídia online sobre os acidentes entre veículos e animais em rodovias brasileiras: uma questão de segurança? Revista Desenvolvimento e Meio Ambiente, 33:261-276, 2015. 
GLOBO COMUNICAÇÃO (Sergipe) (ed.). Quantidade de acidentes com animais cai pela metade em Sergipe. G1 SE. [Aracajú], 22 maio 2014. Disponível em: <http://g1.globo.com/se/sergipe/noticia/2014/ 05/quantidade-de-acidentes-com-animais-caipela-metade-em-sergipe.html>. Acesso em: 11 nov. 2016.

IPEA - Instituto de Pesquisa Econômica Aplicada. Relatório de Pesquisa. Acidentes de Trânsito nas Rodovias Federais Brasileiras Caracterização, Tendências e Custos para a Sociedade. Brasília, 2015. 42 p. Disponível em:<http://www.ipea.gov.br/portal/index.php ?option=com_content $\&$ view $=$ article $\&$ id $=262$ 77> Acesso em: 13 nov. 2016.

Kaiser, G. Delincuencia de tráfico y prevención general. Investigaciones sobre la criminología y el derecho penal del tráfico. Madrid: Espasa-Calpe, 1979. 556p.

Langley, R. L.; Higgins, S. A.; Herrin, K. B. Risk factors associated with fatal animal-vehicle collisions in the United States, 1995-2004. Wilderness \& Environmental Medicine, 17:229-239, 2006.
Leger, D. The cost of sleep-related accidents: A report for the National Commission on Sleep Disorders Research. Sleep, 17:84-93, 1994.

Marín L.; Queiroz, M. S. A atualidade dos acidentes de trânsito na era da velocidade: uma visão geral. Cadernos de Saúde Pública, 16:7-21, 2000.

PRF - Polícia Rodoviária Federal. Estatísticas: Relatório 2010-2014. 2014. Disponível em: $<$ https://www.prf.gov.br/portal/policiamentoe-fiscalizacao/estatisticas>. Acesso em: 15 out. 2016.

Reis, C. Animais em vias públicas e a responsabilidade dos respectivos donos. Revista Jurídica Cesumar, 2:5-9, 2003.

Višnjiæ, V.; Pušiæ, M. Analysis of traffic accidents in the area of small towns in the Republic of Croatia. Traffic \& Transportation, 21(2):129-140, 2009.

WHO. World Health Organization. The epidemiology of road traffic accidents. Copenhagen: WHO Regional Office for Europe, 1976. 38p. 